UNIVERSIDADE DE SÃO PAULO

FACULDADE DE ODONTOLOGIA DE RIBEIRÃO PRETO

GABRIELA SOLANO TANTA

EFEITO DA BIOMODIFICAÇÃO COM CARBODIIMIDA E QUITOSANA FOSFORILADA NA DENTINA AFETADA POR CÁRIE 

GABRIELA SOLANO TANTA

\title{
EFEITO DA BIOMODIFICAÇÃO COM CARBODIIMIDA E QUITOSANA FOSFORILADA NA DENTINA AFETADA POR CÁRIE
}

\author{
Dissertação apresentada à Faculdade de Odontologia de \\ Ribeirão Preto da Universidade de São Paulo, para a obtenção \\ do título de Mestre em Ciências, no Programa: Odontologia \\ Restauradora, Área de concentração: Odontologia Restauradora \\ - Dentística.
}

Orientadora: Profa. Dra. Silmara Aparecida Milori Corona

Ribeirão Preto

2017 
Autorizo a reprodução e divulgação total ou parcial deste trabalho, por qualquer meio convencional ou eletrônico, para fins de estudo e pesquisa, desde que citada a fonte.

Catalogação da Publicação

Serviço de Documentação Odontológica

Faculdade de Odontologia de Ribeirão Preto

Tanta, GS

Efeito da biomodificação com carbodiimida e quitosana fosforilada na dentina afetada por cárie. Ribeirão Preto, 2017.

84 p. : il. ; $30 \mathrm{~cm}$

Dissertação de Mestrado, apresentada ao Programa de PósGraduação em Odontologia Restauradora. Área de concentração: Dentística. Faculdade de Odontologia de Ribeirão Preto/USP.

Orientadora: Corona, Silmara Aparecida Milori.

1. Quitosana. 2. Carbodiimida. 3. Dentina afetada. 4. Microdureza.

5. Microtração. 
FOLHA DE APROVAÇÃO

Nome: Tanta, Gabriela Solano

Título: Efeito da biomodificação com carbodiimida e quitosana fosforilada na dentina afetada por cárie.

Dissertação apresentada à Faculdade de Odontologia de Ribeirão Preto da Universidade de São Paulo, para obtenção do título de Mestre em Ciências.

Aprovada em

\section{Banca Examinadora}

$\operatorname{Prof}(a)$.

$\operatorname{Dr}(\mathrm{a})$

Instituição:

Julgamento:

Assinatura

Prof(a).

$\operatorname{Dr}(\mathrm{a})$.

Instituição:

Julgamento:

Assinatura:

Prof(a).

Dr(a).

Instituição:

Julgamento:

Assinatura

Prof(a).

$\operatorname{Dr}(\mathrm{a})$.

Instituição:

Julgamento:

Assinatura: 

DADOS CURRICULARES

\section{GABRIELA SOLANO TANTA}

Nascimento 11 de Novembro de 1990. Lima - Peru.

Filiação Virginia Tanta de Solano

Juan Francisco Solano Ampa

2007-2011 Curso de Graduação

Universidad Peruana Cayetano Heredia (UPCH)

2012-2013 Curso de aperfeiçoamento em Odontologia Restauradora y Estética

Universidad Peruana Cayetano Heredia (UPCH) 


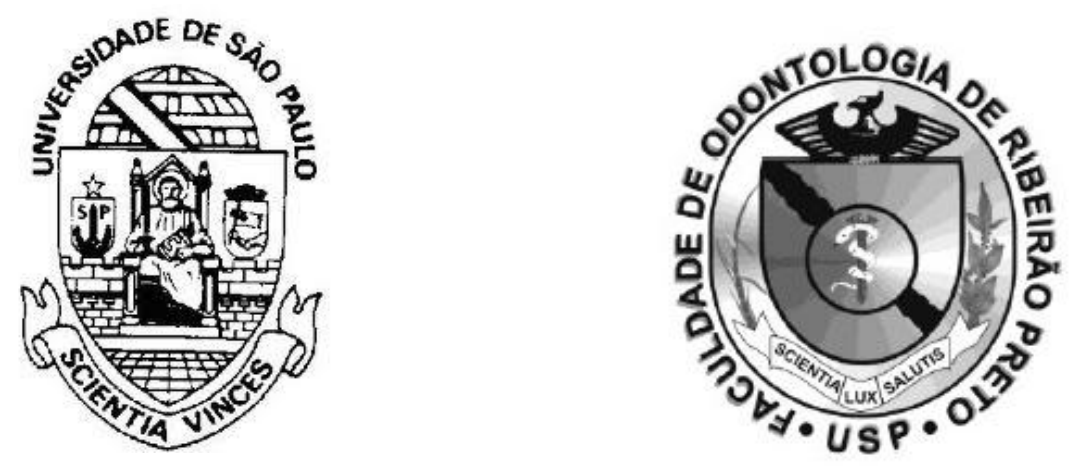

Este trabalho foi realizado nos Laboratórios de Pesquisa em Dentística do Departamento de Odontologia Restauradora da Faculdade de Odontologia de Ribeirão Preto da Universidade de São Paulo, com auxílio da Coordenação de Aperfeiçoamento de Pessoal de Nível Superior (CAPES). 

(2)dicatória 

A Deus, que por sua infinita bondade e sabedoria nos concede, a cada dia, a oportunidade de melhorar naquilo que escolhemos fazer em nossas vidas. Ele que torna possível a possibilidade de enfrentar obstáculos jamais imaginados e que generosamente tem colocado em meu caminho pessoas maravilhosas e iluminadas em meu caminho.

Aos meus amados pais Virginia e Juan por tudo. É impossível descrever em palavras todos as emoções que eu sinto por vocês. Tudo o que eu sou e o que eu aprendi devo a vocês. Obrigada pela compreensão, por sempre me apoiar em todas as decisões difíceis da minha vida, mesmo assim isso tenha significado ficar afastados por mais de $4000 \mathrm{~km}$. Mais uma vez obrigada por seu amor incondicional e a confiança que sempre depositaram em mim.

A meu irmão Diego, pela amizade, companheirismo e amor. Por me brindar todo teu carinho e ajuda. Mesmo sendo uma pessoa de poucas palavras, sempre que preciso de uma luz para me guiar, você só tem as palavras certas para mim. 

Agradecimentos Suspeciais 

À minha querida orientadora Profa. Dra. Silmara Aparecida Milori Corona, a quem admiro muito. Obrigada por me orientar, amparar e acreditar em mim desde o momento em que cheguei a USP, por todas as oportunidades que você já me deu, pelos conselhos e por todo aprendizado que a senhora me passa. Você é um profissional excelente e um exemplo de pessoa com um grande coração. Sempre me sentirei privilegiada de ter sido sua aluna e agradeço pela confiança em mim depositada para a realização deste trabalho.

"Talvez não tenha conseguido fazer o melhor, mas lutei para que o melhor fosse feito. Não sou o que deveria ser, mas Graças a Deus, não sou o que era antes". (Adaptado de Marthin Luther King) 


À Faculdade de Odontologia de Ribeirão Preto - USP, pela oportunidade de realização do curso de Pós-graduação, nível Mestrado, Área de concentração Odontologia Restauradora.

À Coordenação Geral da Pós-Graduação da Faculdade de Odontologia de Ribeirão Preto - USP, na pessoa da Prof. Dr. Prof. Dr. Manoel Damião de Sousa Neto.

Ao Chefe do Departamento de Odontologia Restauradora da Faculdade de Odontologia de Ribeirão Preto, na pessoa do Prof. Dr. Ricardo Gariba Silva.

À coordenação de Aperfeiçoamento do Pessoal de Nível Superior (CAPES), do Ministério da Educação, pela concessão da bolsa de mestrado e pelo apoio financeiro para a realização desta pesquisa.

Aos Professores do Departamento de Odontologia Restauradora da Faculdade de Odontologia de Ribeirão Preto - USP.

Às Professoras Dra. Aline Evangelista Souza Gabriel e Dra. Regina Guenka Palma-Dibb, obrigada pelo acolhimento, orientações e ensinamentos transmitidos e divididos conosco.

À Professora Arlete Barbosa dos Reis da Universidade Federal dos Vales do Jequitinhonha e Mucuri, pela colaboração e auxilio na confecção da quitosana fosforilada.

Aos funcionários da Secção de Pós-Graduação da Faculdade de Odontologia de Ribeirão Preto da Universidade de São Paulo, pela atenção dispensada e eficiência com que sempre nos atenderam.

Aos funcionários do Departamento de Odontologia Restauradora da Faculdade de Odontologia de Ribeirão Preto da Universidade de São Paulo: Patrícia Marchi e Reginaldo Santana, pela atenção e colaboração durante o mestrado. 
Ao Carlos, secretário do Curso de Pós-Graduação em Odontologia da Faculdade de Odontologia de Ribeirão Preto da Universidade de São Paulo, pelo empenho e simpatia com que realiza seu trabalho, e ajuda na resolução dos problemas

Ao técnico Edson Volta do laboratório LIPEN, pela paciência, disposição e carinho durante a execução dos testes de microtração.

À Ana Paula Macedo, técnica do Departamento de Materiais Dentários da Faculdade de Odontologia de Ribeirão Preto da Universidade de São Paulo, pela disponibilidade imediata e valioso auxílio com parte da análise estatística realizada neste trabalho.

À Minha Família que nunca duvidou da minha capacidade e que sempre torceu por mim, mesmo de longe tem dividido comigo minhas alegrias e penas. Obrigada por todo seu carinho e amor.

À Fabiana Curylofo, por ter me apoiado em cada etapa deste trabalho, sempre acreditando que eu era uma pessoa capaz. Me ensinando o valor do trabalho constante e da paciência. Por me dar calma nos momentos de mais dificuldade. Foi um prazer trabalhar ao teu lado, fico grata de você ter me ensinado sobre como ser uma pesquisadora. Agradecida por tua amizade e teu profissionalismo.

À querida Thaís Fillus, obrigada por me brindar tua companhia todo este tempo, definitivamente sem você a experiência não teria sido a mesma. Fico muito agradecida por ter te conhecido e que Deus tenha colocado no meu caminho uma pessoa de tão bom coração. Obrigada por sempre confiar em mim, pelo companheirismo e sua caraterística honestidade. Amiga, colega e vizinha, sempre pronta para escutar e dar consolo. Sempre ficará na minha memória o inúmero de vezes que saímos tarde do laboratório com a luz da lua para nos iluminar, as vezes que saímos para comer, as vezes que viajamos e que demos risada. Por me fazer sentir esse calor familiar, mesmo estando longe de casa. 
Às minhas queridas amigas da Dentística: Tatiana Carvalho e Shelyn Yamakami, vocês são um presente de Deus. Agradeço cada experiência vivenciada com vocês, por todos os momentos únicos, por sempre alegrar meus dias e tornar minha estadia em Ribeirão Preto mais agradável. Sempre penso em vocês como minha família brasileira, porque é assim que eu me sinto com vocês.

Aos queridos amigos do Departamento de Odontologia Restauradora que a FORP me deu: Daniel Filizola, Julia Gallas, Mirian Saavedra, Reinaldo Dias, Diego Brandariz, pelo companheirismo, apoio e amizade durante todo curso de Pós-Graduação.

A todos os colegas de Pós-Graduação, pela agradável convivência e disponibilidade em ajudar sempre.

A todos os colaboradores que direta ou indiretamente contribuíram para que a realização deste trabalho fosse possível. 

Qesumo 



\section{RESUMO}

Tanta, GS. Efeito da biomodificação com carbodiimida e quitosana fosforilada na dentina afetada por cárie. 2017. 84f. Dissertação (Mestrado) - Faculdade de Odontologia de Ribeirão Preto, Universidade de São Paulo, Ribeirão Preto, 2017.

O objetivo do presente estudo foi avaliar o efeito da biomodificação com carbodiimida e quitosana fosforilada na dentina afetada por cárie. A amostra foi composta por 75 espécimes de dentina bovina submetidos à indução de lesão de cárie pelo método de ciclagem do pH (8h em solução desmineralizante e 16h em solução remineralizante) durante 14 dias. Foi realizada a remoção seletiva da lesão de cárie com broca em baixa rotação. Os espécimes foram divididos de acordo com a biomodificação da dentina: sem biomodificação (controle), carbodiimida (EDC) e quitosana fosforilada (P-chi). Os espécimes foram condicionados com ácido fosfórico $35 \%$, e tratados com o agente biomodificador correspondente. Os espécimes foram restaurados com adesivo (Single Bond Universal - 3M ESPE) e resina composta (Z250 - 3M ESPE). Trinta espécimes foram submetidos à análise de microdureza da subsuperfície dentinária em quatro momentos: dentina hígida, dentina afetada por cárie, após a remoção seletiva da lesão de cárie (dentina residual) e, após a restauração dos espécimes. Os 36 espécimes restantes foram submetidos a ensaio de resistência de união à microtração ( $\mu$ TBS) realizado após 24 h e 6 meses de armazenamento em água e microscopia eletrônica de varredura (MEV). Os dados foram analisados por meio de testes paramétricos e não paramétricos $(\alpha=0,05)$. A biomodificação da dentina residual afetada por cárie com EDC e P-chi não alterou a microdureza da subsuperfície dentinária $(p=0,141)$. Na análise de $\mu$ TBS, não foram encontradas diferenças significativas entre os grupos $24 \mathrm{~h}$ e após 6 meses de armazenamento. Ao longo do tempo, o grupo controle $(p<0,001)$ teve redução da $\mu T B S$, o grupo EDC $(p=0,099)$ foi capaz de manter a $\mu$ TBS e o grupo $P$-chi $(p=0,005)$ promoveu aumento da $\mu$ TBS. A análise de MEV mostrou que os biomodificadores preservaram a interface adesiva após 6 meses de armazenamento. A biomodificação com carbodiimida e quitosana fosforilada não influenciou a microdureza da subsuperfície da dentina afetada por cárie, porém foi capaz de inibir a degradação da interface adesiva, mantendo a resistência de união da resina composta à dentina afetada após 6 meses de armazenamento em água. 
Palavras-chave: Quitosana, Carbodiimida, Dentina afetada, Microdureza, Microtração. 


\begin{abstract}
Tanta, GS. Effect of biomodification with carbodiimide and phosphorylated chitosan, over caries affected dentin. 2017. 84f. Dissertação (Mestrado) - Faculdade de Odontologia de Ribeirão Preto, Universidade de São Paulo, Ribeirão Preto, 2017.
\end{abstract}

The aim of this study was to evaluate in vitro the effect of biomodification with carbodiimide and phosphorylated chitosan on caries affected dentin. The sample was composed by 75 bovine incisors, submitted to caries induction by $\mathrm{pH}$ cycling (8h in demineralizing solution and $16 \mathrm{~h}$ in remineralizing solution) for 14 days. The selective caries removal was performed with bur at low-speed handpiece. Specimens were divided according to the dentin biomodification: no biomodification (control), carbodiimide (EDC) and phosphorylated chitosan (P-chi). All specimens were conditioned with 35\% phosphoric acid and then treated with the correspondent biomodificator. Specimens were restored with an adhesive system (Single Bond Universal - 3M ESPE) and composite resin (Z250 - 3M ESPE). Thirty specimens were submitted to subsurface microhardness test in four periods of time: on sound dentin, on caries-affected dentin, after the selective removal of caries (residual caries-affected dentin) and after the restoration. The remaining 36 specimens were submitted to microtensile bond strength test ( $\mu$ TBS) after $24 \mathrm{~h}$ and 6 months of water storage and to scanning electron microscopy analysis (SEM). Data were statistically analyzed by parametric and non-parametric tests $(\alpha=0.05)$. The biomodification of residual caries-affected dentin with EDC and P-chi did not change the subsurface microhardness $(p=0.141)$. In the $\mu$ TBS test, there were no significant difference between groups at $24 \mathrm{~h}$ and 6 months of water storage. Over time, the control group $(p<0.001)$ had a decreased on the $\mu$ TBS, the EDC group $(p=0.099)$ was capable of maintained $\mu$ TBS and the $P$-chi group $(p=0.005)$ increased in $\mu$ TBS. SEM analysis showed that biomodification preserved the adhesive interface after 6 months of water storage. The biomodification with carbodiimide and phosphorylated chitosan did not influence the subsurface microhardness of caries-affected dentin, however, it was capable of inhibit degradation of the adhesive interface, maintaining the microtensile bond strength of the composite resin to caries affected dentin after 6 months of water storage.

Key-words: Chitosan, Carbodiimide, Caries affected dentin, Microhardness, Microtensile. 

Osumário 



\section{SUMÁRIO}

Resumo

Abstract

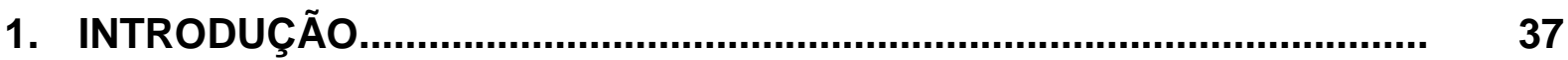

2. PROPOSIÇÃO....................................................................................

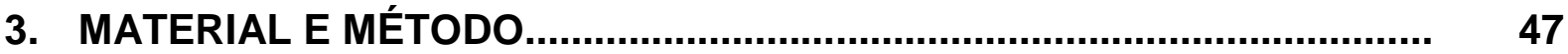

Delineamento experimental.............................................................. 49

Seleção dos dentes....................................................................... 49

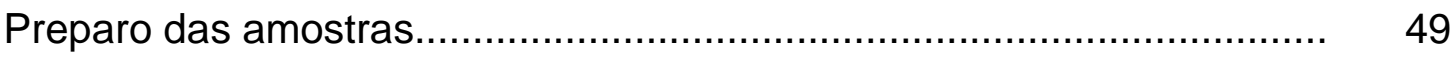

Microdureza inicial para seleção dos espécimes (dentina hígida)............ 50

Indução das lesões de cárie artificial.................................................... 51

Divisão dos grupos experimentais...................................................... 51

Remoção seletiva das lesões de cárie................................................. 51

Preparo da solução de quitosana fosforilada (P-chi) 2,5\%...................... 52

Preparo da solução de Carbodiimida (EDC) $0.5 \mathrm{~mol} / \mathrm{L}$........................... 53

Biomodificação da dentina e procedimento restaurador........................... 54

Análise da microdureza após a biomodificação e restauração dos espécimes

Secção dos espécimes e envelhecimento da interface adesiva............... 55

Ensaio de resistência de união a microtração $(\mu$ TBS) ............................. 56

Microscopia Electrónica de Varredura da interface adesiva..................... 57

Análise estatística..................................................................... 58

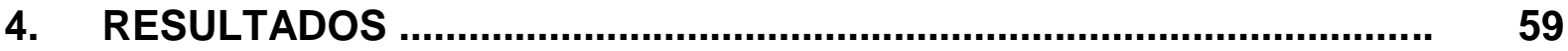

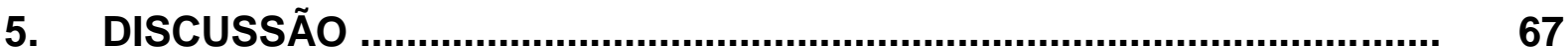




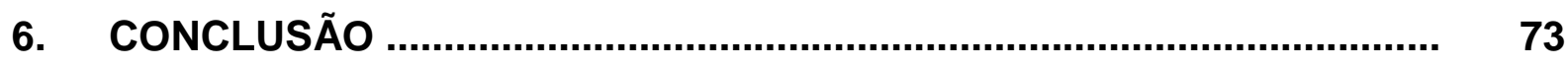

REFERÊNCIAS......................................................................................... 
จntroduçã்o 



\section{INTRODUÇÃO}

A preservação do substrato dentário sadio é um dos princípios fundamentais da odontologia minimamente invasiva (TYAS et al., 2000; WALSH et al., 2013). A distinção clínica entre a camada mais externa (ou dentina infectada) e a camada mais interna (ou dentina afetada), passível de remineralização (FUSAYAMA, 1979), permite evitar a remoção desnecessária de estrutura dental, favorecendo os procedimentos adesivos (KIDD, 2004), além disso, promove menor risco de exposição pulpar (RICKETTS et al., 2006; THOMPSON et al., 2008), estimulando o processo de esclerose tubular e deposição de dentina terciária, reduzindo assim a permeabilidade da dentina remanescente (KIDD, 2004).

Substâncias biomodificadoras tem sido utilizadas com o intuito de melhorar a resistência mecânica do colágeno, componente principal da dentina; e aumentar a resistência à degradação hidrolítica e enzimática das fibrilas colágenas, utilizadas como suporte para o estabelecimento das interfaces adesivas (BEDRAN-RUSSO et al., 2014; SCHEFFEL et al., 2014a; TJÄDERHANE, 2015). A estratégia utilizada de alguns agentes biomodificadores são as ligações cruzadas ou crosslinks; as quais consistem na união de duas ou mais moléculas mediante ligações químicas do tipo covalentes (ZEEMAN et al., 1999; TJÄDERHANE et.al, 2013; MAZZONI et al., 2014).

A Carbodiimida (1-Etil-3-[3-dimetilaminopropil] hidroclorito de carbodiimida ou EDC) é um isômero de cianamida com a capacidade de agregar aminoácidos em peptídeos (BEDRAN-RUSSO et al., 2010), sem a incorporação de outros grupos ao processo de ligação. A EDC possui baixa citotoxicidade, com um mecanismo de ação que promove ligações peptídeo-covalentes entre as proteínas, ativando os grupos carboxilo livres nos ácidos glutâmico e aspártico presentes nas moléculas proteicas (SCHEFFEL et al., 2014b; SCHEFFEL et al., 2015). Estas ligações resultam na formação de O-acilisourea, que irá reagir com a lisina ou hidroxilisina presente na cadeia polipeptídica mais próxima e formar ligações amida covalentes (EKAMBARAM; YIU; MATINLINNA, 2015). O único produto residual deste processo é a ureia, mas é facilmente eliminado com água. $O$ uso da carbodiimida sobre colágeno confere alto grau de ligações cruzadas; por tanto, maior resistência à degradação enzimática quando exposta as colagenases (OLDEDAMINK et al., 1996). 
Diante a esta importante característica da EDC, este composto foi inserido no campo da odontologia como agente promotor de ligações cruzadas, proposto para melhorar a estabilidade mecânica e estrutural do colágeno dentinário, permitindo a formação de uma rede estável da matriz dentinária, a qual pode ser infiltrada com resina, promovendo uma camada híbrida estável e com maior longevidade (BEDRANRUSSO et al., 2010; MAZZONI et al., 2013; SHAFIEI; YOUSEFIPOUR; MOHAMMADI-BASSIR, 2016; SINGH et al., 2016).

A carbodiimida exibe vantagens em relação a outros agentes inibidores de atividade proteolítica, pois não atua somente em enzimas, mas também faz ligações cruzadas com as moléculas de colágeno. Outra vantagem seria que este agente por ser inespecífico, atua sobre um amplo espetro de enzimas do tipo colagenase (MMPs, catepsinas e outras), não necessitando, portanto, da utilização de diferentes tipos de agentes para cada uma destas enzimas (SABATINI; PASHLEY, 2014).

A quitosana é outro agente biomodificador o qual é obtido por meio de desacetilação alcalina da quitina; sendo o principal componente do exoesqueleto dos crustáceos (MUZZARELLI et al., 1973). Este biopolímero é composto por copolímeros $\beta$-(1-4)-D-glucosamina e N-acetil-D-glucosamina, com dois grupos hidroxil livres e um grupo amino primário em cada unidade estrutural C6 (ELSAKA; ELNAGHY, 2012; LONGHI et al., 2015). Os grupos amino presentes conferem à quitosana carga positiva (catiônico); dando a esta, uma alta reatividade sobre partículas ou superfícies aniônicas (por exemplo, bactérias e biofilmes), conferindoIhe a propriedade antimicrobiana (SANO et al., 2001; ELSAKA; ELNAGHY, 2012). Além isso, a quitosana é um composto biocompatível, que tem a capacidade de estimular a proliferação de fibroblastos (MORI et al., 1997; WANG et al., 2003; TANGSADTHAKUN et al., 2007; LAUTO et al., 2010) e ação quelante (RABEA et al., 2003; SILVA et al., 2012).

Devido à estrutura química da quitosana é possível preparar inúmeros derivados a partir deste composto, como a quitosana fosforilada (BERNKOPSCHNÜRCH, 2012). Este biopolímero modifica a superfície do colágeno, facilitando o processo de remineralização da dentina desmineralizada (WANG et al. 2003; XU et al., 2011). 
Os grupos fosfato presentes na quitosana fosforilada podem se juntar aos íons de cálcio para formação de sítios de nucleação e induzir a formação de uma camada de fosfato de cálcio (YOKOGAWA et al. 1997; CHESNUTT et al. 2007). Assim, membranas de quitosana fosforilada poderiam induzir a deposição biomimética de uma camada parecida à apatita sob condições fisiológicas simuladas (YOKOGAWA et al. 1997; CHESNUTT et al. 2007), promovendo a remineralização da dentina desmineralizada (XU et al., 2011).

Assim, diante da necessidade de preservação da dentina, torna-se importante avaliar o efeito de compostos biomodificadores (Quitosana fosforilada e Carbodiimida), que apresentam resultados promissores já demonstrados pela literatura, na dentina afetada por cárie, com a finalidade de melhorar a integridade estrutural e a resistência da interface adesiva. 




\section{PROPOSIÇÃO}

Este estudo in vitro teve como objetivo avaliar o efeito da biomodificação com carbodiimida e quitosana fosforilada na dentina afetada por cárie por meio de:

1. Análise da microdureza da subsuperfície dentinária.

2. Análise da resistência de união da interface adesiva e sua morfologia após 24h e 6 meses de armazenamento em água. 



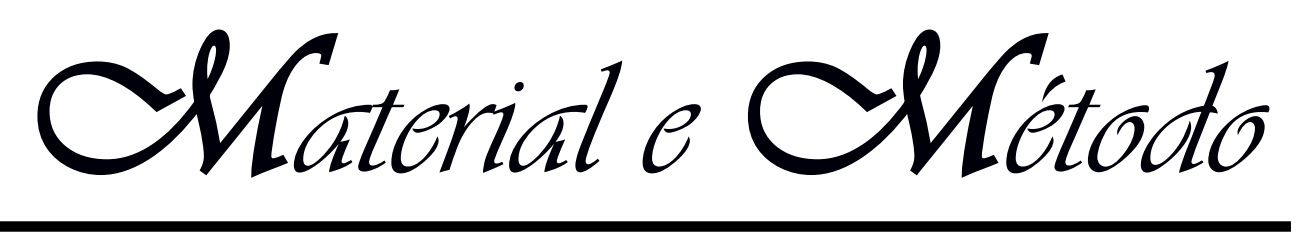





\section{MATERIAL E MÉTODO}

\section{Delineamento Experimental}

Os fatores em estudo foram a biomodificação da dentina em três níveis: carbodiimida (EDC), quitosana fosforilada (P-chi) e sem biomodificação (controle). Foram inclusos na amostra do experimento 75 incisivos bovinos divididos aleatoriamente em 3 grupos. O delineamento foi em blocos completos casualizados. As variáveis de resposta foram: 1) análise quantitativa (KHN) da microdureza da subsuperfície dentinária $(n=10), 2)$ análise quantitativa da resistência de união à microtração da interface resina/dentina e avaliação das falhas após 24 horas e 6 meses de envelhecimento ( $n=12)$ e 3 ) análise qualitativa da morfologia da interface adesiva após 24 horas e 6 meses de envelhecimento $(n=3)$.

\section{Seleção dos dentes}

Foram utilizados incisivos bovinos conservados em solução de timol $0,1 \%$ a $9^{\circ} \mathrm{C}$. Os quais foram lavados em água corrente por 24 horas e eliminar os resíduos de timol, e examinados macroscopicamente com auxílio da lupa estereoscópica (Leica Microsystems, Wetzlar, Alemanha) em aumento de 20x. Foram selecionados 75 incisivos que não apresentavam linhas de fratura ou fissuras profundas na coroa.

\section{Preparo das amostras}

Os dentes tiveram as coroas separadas das raízes por meio de sua secção transversal na junção amelocementária, utilizando disco diamantado montado em máquina de corte (Isomet 1000; Buehler, Alemanha). Em seguida, as coroas dentais foram seccionadas longitudinalmente no sentido mésio-distal. A hemi-secção da face vestibular da coroa de cada dente foi seccionada de forma a se obter 1 espécime de $7 \times 7 \times 2,5 \mathrm{~mm}$ de dentina da face vestibular de cada coroa. Os espécimes obtidos foram devidamente fixados em matrizes de teflon empregando-se cera fundida, de modo que as superfícies de dentina permanecessem voltadas para o meio externo. As superfícies de dentina foram polidas em Politriz giratória (DP-9U2; Struers S/A, Copenhagen, Dinamarca) refrigerada à água com lixas d'agua de granulação 1200 
(Hermes 12 Abrasives Ltd., VA, EUA) e pasta de alumina $0.3 \mu \mathrm{m}$ e $0.05 \mu \mathrm{m}$ (Arotec S/A Ind. Com., São Paulo, Brasil) em feltro polidor (ATM, Altenkirchen, Alemanha) (HARA et al., 2003).

\section{Microdureza inicial para seleção dos espécimes (dentina hígida)}

Para que os espécimes pudessem ser incluídos no estudo, foi realizado um processo de seleção e padronização dos valores de microdureza das subsuperfícies dentais. Para a mensuração da microdureza foi utilizado o microduromêtro HMV2000 (Shimadzu Corporation, Kyoto, Japão), com penetrador de diamante para dureza Knoop (KHN) e célula de carga de 25 gramas durante 5 segundos (RODRIGUES; NOBRE DOS SANTOS; FEATHERSTONE, 2006) (Figura 1). Foram realizadas três endentações na lateral dos espécimes (subsuperfícies), com espaços pré-programados de $30 \mu \mathrm{m}$ da superfície e $100 \mu \mathrm{m}$ uma da outra (HARA et al., 2003). A média das medidas foi utilizada como valor de microdureza do espécime sendo que aqueles que apresentaram valores médios acima ou abaixo de $20 \%$ foram descartados (HARA et al., 2006). Os espécimes incluídos tiveram uma média de microdureza de knoop (KHN) de $54 \mathrm{MPa}$.
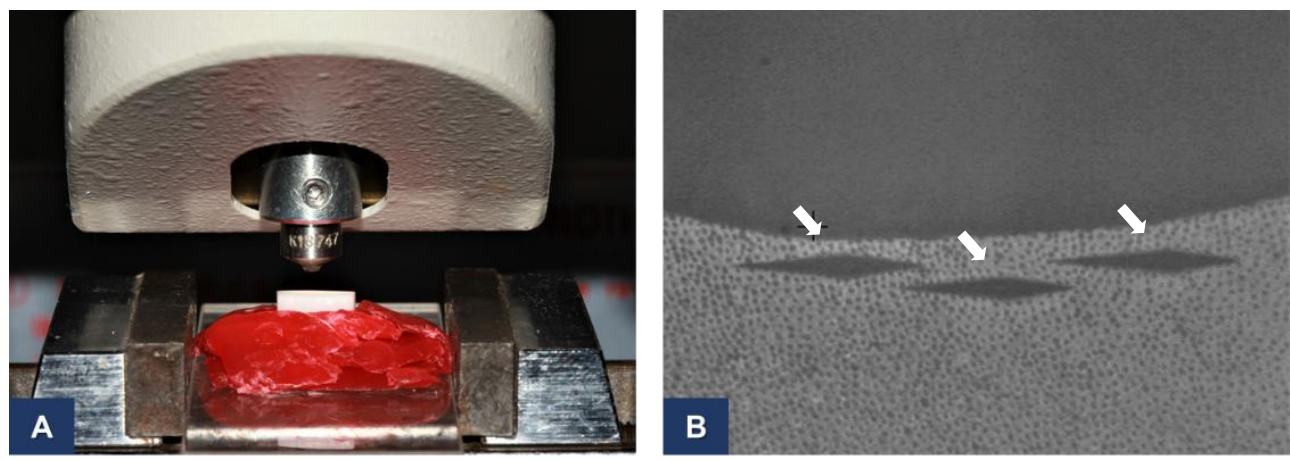

Figura 1 - Análise de microdureza inicial. (A) Posicionamento do espécime no microduromêtro para análise da face lateral. (B) Medição da microdureza inicial da dentina com assistência do ordenador. $\Rightarrow$ Indica as endentações da ponta do microdurômetro. 


\section{Indução das lesões de cárie artificial}

As lesões de cárie em dentina foram formadas artificialmente por meio de ciclagem do $\mathrm{pH}$, conforme protocolo descrito por Marquezan et al. (2009). Foram utilizadas uma solução desmineralizante e outra remineralizante, sendo o conteúdo da solução desmineralizante $2 \mathrm{mM}$ de $\mathrm{CaCl}_{2}, 2.2 \mathrm{mM}$ de $\mathrm{NaH}_{2} \mathrm{PO}_{4}$ e $50 \mathrm{mM}$ de ácido acético com pH ajustado para 4.8. E a solução remineralizante foi composta por 1.5 $\mathrm{mM}$ de $\mathrm{CaCl}_{2}, 0.9 \mathrm{mM}$ de $\mathrm{NaH}_{2} \mathrm{PO}_{4}$ e $0.15 \mathrm{M}$ de $\mathrm{KCl}$ com $\mathrm{pH}$ em torno de 7.0. Cada espécime foi ciclado em $10 \mathrm{~mL}$ de solução, sendo $8 \mathrm{~h}$ em solução desmineralizante e $16 \mathrm{~h}$ em solução remineralizante. Este procedimento foi realizado por 14 dias em temperatura ambiente. A análise de microdureza da subsuperfície de dentina afetada por cárie foi realizada na lateral dos fragmentos, conforme descrito na análise da microdureza inicial.

\section{Divisão dos grupos experimentais}

Os espécimes foram aleatoriamente divididos em três grupos de acordo com a biomodificação da dentina da dentina: carbodiimida (EDC), quitosana fosforilada (P-chi) e sem biomodificação (controle). Dos 75 espécimes de dentina, 30 foram destinados à análise de microdureza da subsuperfície dentinária, 36 à análise de resistência de união à microtração, e 9 à análise de microscopia eletrônica de varredura.

\section{Remoção seletiva das lesões de cárie}

A remoção seletiva do tecido cariado foi realizada na camada superficial da dentina cariada, utilizando brocas carbide esféricas (KG Sorensen, Barueri, SP, Brasil), em baixa rotação (Contra-ângulo 1:1 L micro-series, Gnatus, Ribeirão Preto, $\mathrm{SP}$, Brasil) (Figura 2).

Após a remoção seletiva da lesão de cárie, a análise de microdureza da subsuperfície de dentina residual foi realizada na lateral dos espécimes, conforme descrito na análise da microdureza inicial. 

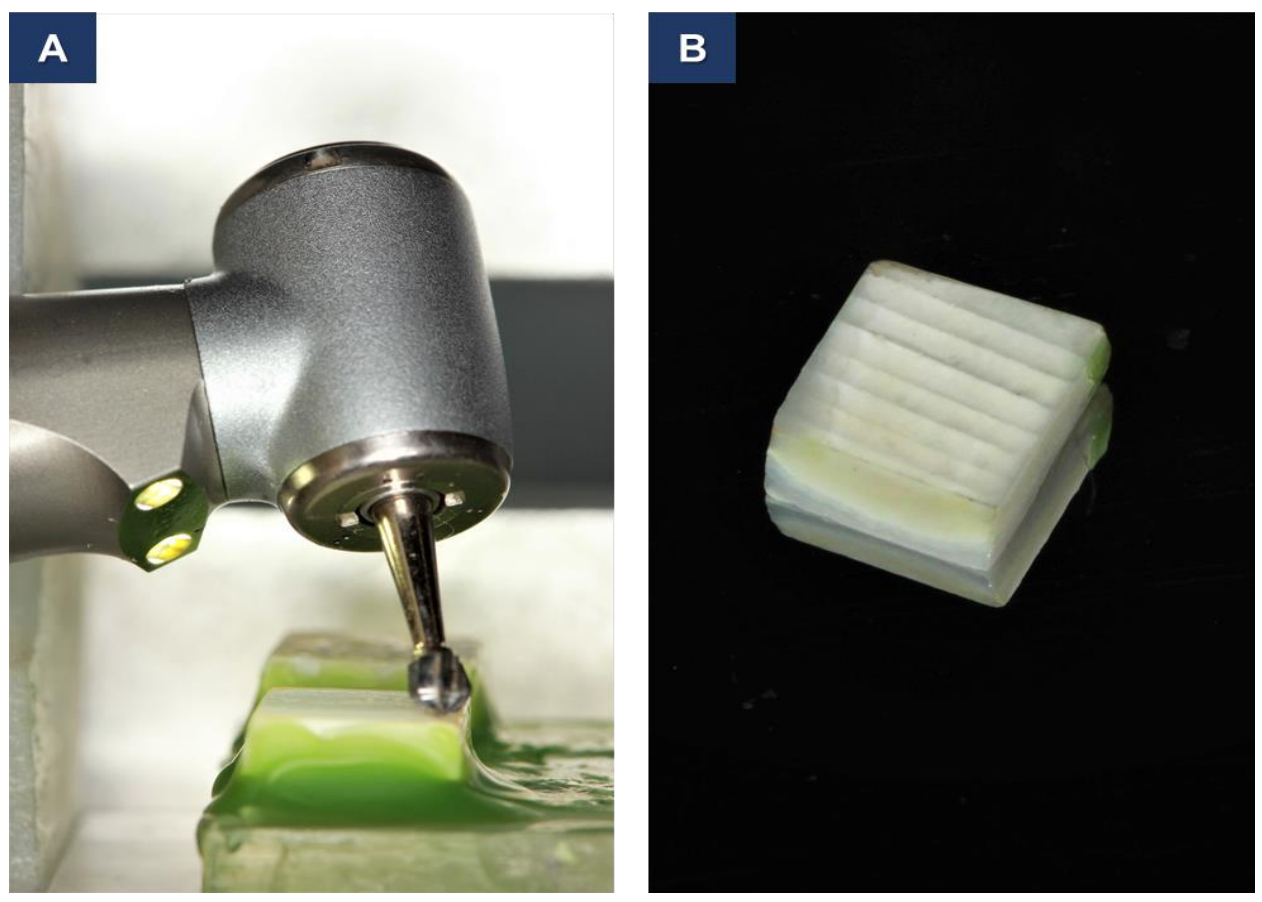

Figura 2 - Remoção seletiva da lesão de cárie em dentina. (A) Broca carbide esférica em baixa rotação (Contra-ângulo 1:1 L micro-series, Gnatus). (B) Imagem do espécime após remoção da lesão de cárie.

\section{Preparo da solução de quitosana fosforilada (P-chi) $2.5 \%$}

Para este estudo foi utilizado quitosana fosforilada (P-chi) 2.5\%, de acordo com o protocolo de Wang e Liu (2014). Foram pesados 2.5 gramas de quitosana (Sigma-Aldrich, Saint Louis, MO, EUA) de baixo peso molecular $(75-85 \%$ de desacetilação) (CHUNG et al., 2016), 5 gramas de ureia e $10 \mathrm{~mL}$ de ácido fosfórico, os quais foram adicionados a $40 \mathrm{~mL}$ de solução de dimetilformamida (DMF). A mistura foi agitada a temperatura de $150^{\circ} \mathrm{C}$ durante 1 hora. Em seguida, foi filtrada, e o precipitado lavado minuciosamente com água destilada e etanol anidro, e então, seco sob vácuo (WANG; LIU, 2014). Tendo como resultado a fosforilação da quitosana, nos grupos amino e hidroxila. O pó de quitosana fosforilada foi elaborado no laboratório do Instituto de Ciência e Tecnologia pela professora Arlete Barbosa dos Reis na Universidade Federal dos Vales do Jequitinhonha e Mucuri.

Para a diluição da quitosana fosforilada, 0,05 gramas de pó foram adicionados lentamente a $2 \mathrm{~mL}$ de solução de ácido acético a $1 \%$, sob agitação 
magnética (Marconi Equip. Lab. Ltda, Piracicaba, SP, Brasil) durante 1 hora de agitação (tempo suficiente para solubilizar o polissacarídeo) (Figura 3).
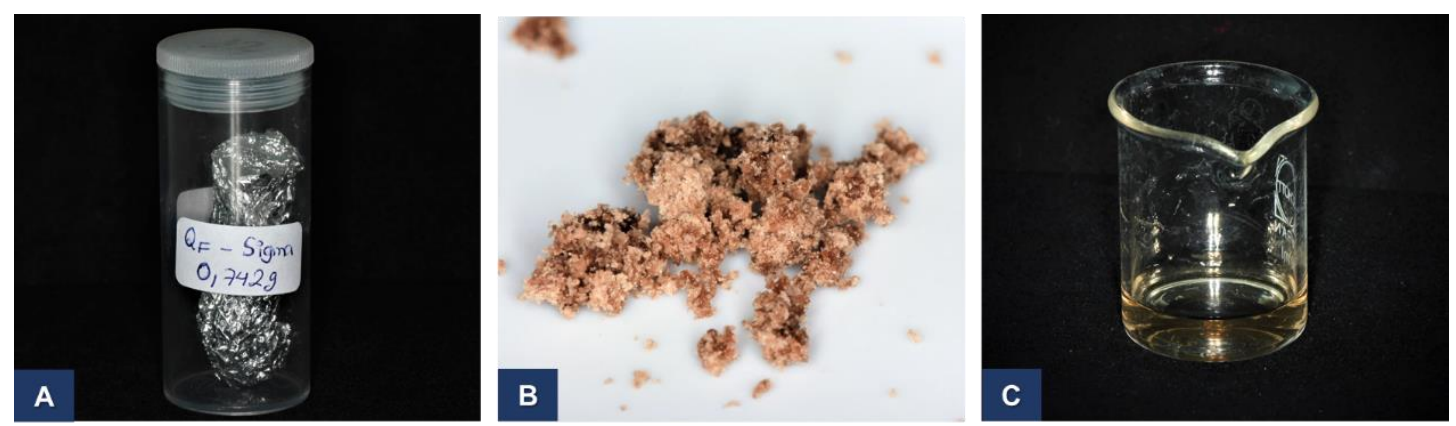

Figura 3 - Quitosana Fosforilada. (A) Forma de armazenamento da quitosana. (B) Pó de quitosana fosforilada. (C) Solução preparada de quitosana fosforilada $2,5 \%$.

\section{Preparo da solução de carbodiimida (EDC) $0.5 \mathrm{~mol} / \mathrm{L}$}

A solução de carbodiimida (EDC) (Sigma-Aldrich, Saint Louis, MO, EUA) foi preparada no momento de ser utilizada. Para obtenção de uma concentração de EDC $0.5 \mathrm{~mol} / \mathrm{L}$, foi necessário preparar por grupo: $2.3 \mathrm{mg}$ de EDC-HCL diluído em $240 \mu \mathrm{L}$ de água milli-q; obtendo-se uma solução com pH 7.34. A solução de Carbodiimida foi preparada no Laboratório de Pesquisas em Dentística do Departamento de Odontologia Restauradora da FORP-USP (Figura 4).
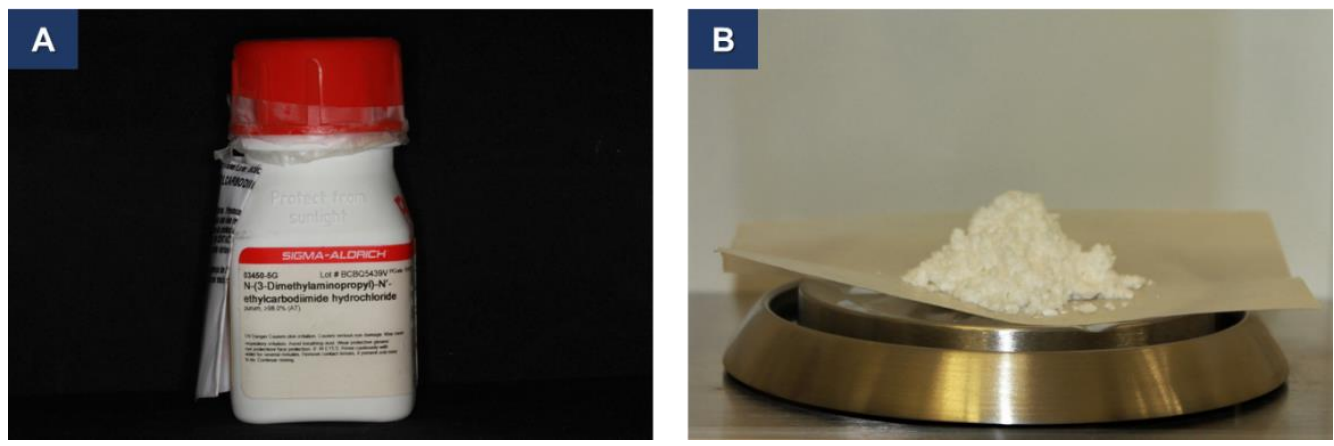

Figura 4 - Hidroclorito de carbodiimida. (A) Apresentação do EDC-HCl da SigmaAldrich. (B) Medição da quantidade de carbodiimida que será utilizada. 


\section{Biomodificação da dentina e procedimento restaurador}

Todos os espécimes receberam condicionamento da dentina com ácido fosfórico a 35\% (Ultra-Etch Ultradent, SP, Brazil) por 15 segundos, seguido de lavagem com água destilada pelo mesmo tempo e secagem com papel absorvente.

Para os espécimes destinados a tratamento com quitosana fosforilada 2,5\%, $20 \mu \mathrm{L}$ da solução de quitosana fosforilada foi aplicada sobre a superfície dentinária durante 60 segundos, e após a superfície foi seca com papel absorvente.

Para o grupo designado a receber tratamento com EDC, $20 \mu \mathrm{L}$ de solução foram aplicados sobre a dentina por 60 segundos (SCHEFFEL et al., 2015), seguido de lavagem durante 15 segundos e secagem com papel absorvente.

O grupo controle não recebeu nenhum tratamento biomodificador.

De acordo com as indicações do fabricante, aplicou-se duas camadas do adesivo (Single bond Universal, 3M ESPE, Joinville, SC, Brazil) com microbrush no 2 (KG Sorensen, São Paulo, SP, Brazil) de forma ativa com posterior evaporação do solvente com jato de ar e fotopolimerização por 10 segundos. A seguir, as superfícies dentinárias dos espécimes foram restauradas com resina composta Filtek Z250 (3M ESPE, St. Paul, MN, EUA) em 2 incrementos com espessura de $2 \mathrm{~mm}$, com auxílio da espátula o 1 (Duflex SS White, Rio de Janeiro, RJ, Brasil) e fotopolimerização (Gnatus Ltda, Ribeirão Preto, SP, Brasil) por 20 segundos em cada incremento. A extremidade ativa da lâmpada polimerizadora foi mantida a $1 \mathrm{~mm}$ de distância da resina com auxílio de dispositivo próprio (Figura 5). 

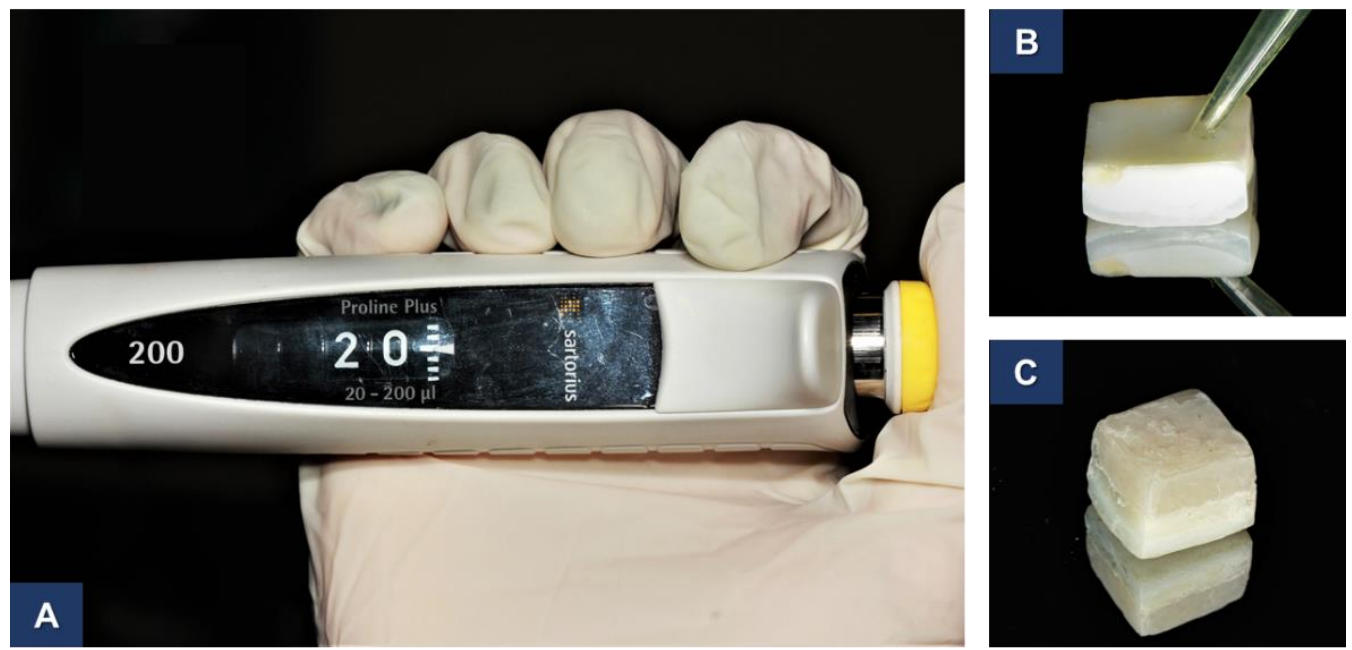

Figura 5 - Procedimento restaurador. (A) Medição de $20 \mu \mathrm{L}$ da solução biomodificadora. (B) Aplicação da solução sobre o espécime com ajuda de micropipeta. (C) Restauração em resina composta.

\section{Análise da microdureza após a biomodificação e restauração dos espécimes}

Os espécimes restaurados foram inclusos em resina acrílica, para ser seccionados longitudinalmente no centro. Em seguida posicionados numa matriz de teflon com cera fundida, e com auxílio do paralelômetro, para serem polidos em Politriz giratória refrigerada (Buehler, Chicago, EUA). O objetivo do polimento foi a obtenção de uma superfície lisa e sem irregularidades, para o qual foram utilizadas lixas de granulação \#1200, finalizando-se com pastas de alumina (Arotec S/A Ind. Com., São Paulo, Brasil) em feltro polidor (ATM, Altenkirchen, Alemanha). Após o polimento, foi escolhida de forma aleatória uma das hemi-seções para o teste de microdureza. Para a mensuração da microdureza foi utilizado o microduromêtro HMV-2000 (Shimadzu Corporation, Kyoto, Japão), com penetrador de diamante para dureza Knoop (KHN) e célula de carga de 25 gramas durante 5 segundos (RODRIGUES; NOBRE DOS SANTOS; FEATHERSTONE, 2006). Foram realizadas três endentações na lateral dos espécimes (subsuperfícies), com espaços préprogramados de $30 \mu \mathrm{m}$ da superfície e $100 \mu \mathrm{m}$ uma da outra (HARA et al., 2003).

\section{Secção dos espécimes e envelhecimento da interface adesiva}

Para seção dos espécimes (conjunto dentina/resina), foram realizadas as etapas a seguir: uso da cortadeira de precisão (Isomet 1000; Buehler, Lake Bluff, IL, 
EUA) com irrigação constante para realização de cortes no sentido ocluso-pulpar. A partir dos fragmentos obtidos, as extremidades foram descartadas, utilizando-se os palitos extraídos da porção central do espécime. Um mínimo de 12 palitos de $1.0 \pm$ $0.2 \mathrm{~mm}^{2}$ de área transversal foram obtidos de cada espécime (PROFETA et al., 2012) (Figura 6). Com o auxílio do paquímetro digital (Mitutoyo, Toquio, Japão), a espessura de cada fragmento foi confirmada. Seis palitos por dente foram destinados ao teste de resistência de união a microtração ( $n=12$ dentes e 72 palitos por grupo) após 24h (imediata) e os 6 palitos restantes foram submetidos a 6 meses de envelhecimento hidrolítico da interface. $O$ envelhecimento hidrolítico consistiu no armazenamento dos palitos em $20 \mathrm{~mL}$ de água destilada a $37^{\circ} \mathrm{C}$ em estufa por um período de 6 meses, com troca da água semanalmente (PROFETA et al., 2012).
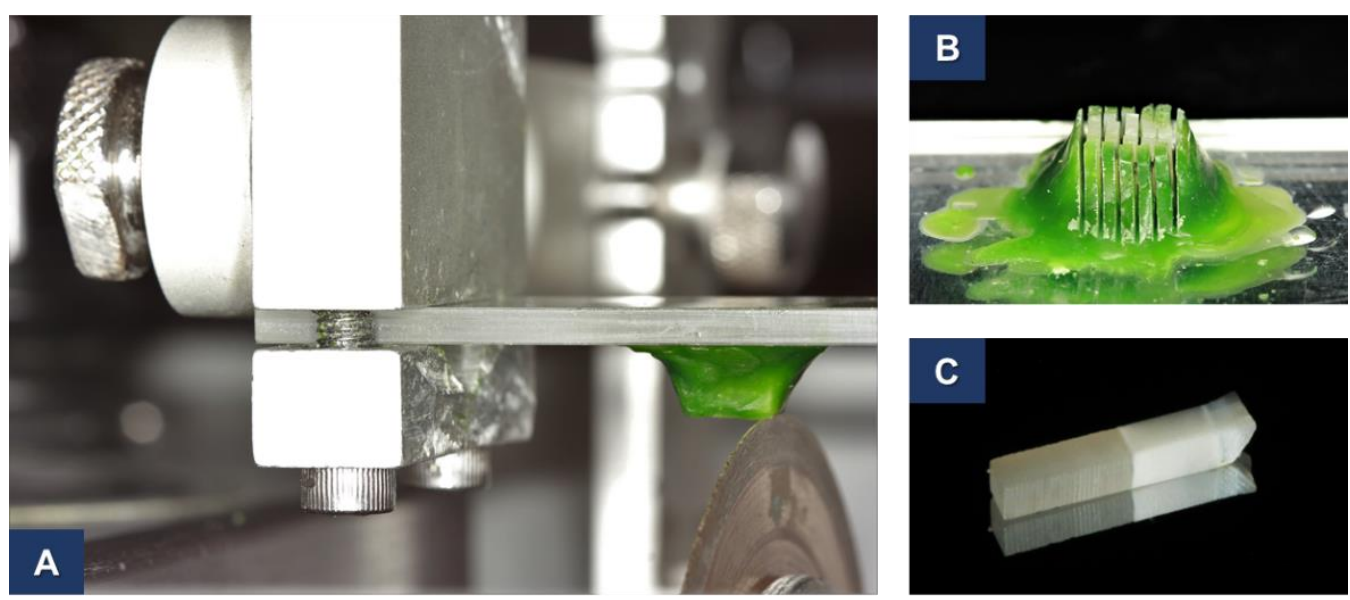

Figura 6 - Secção do conjunto dentina/resina. (A) Utilização da cortadeira de precisão. (B) Seccionamento do espécime restaurado para obtenção de palitos 1,0 \pm $0,2 \mathrm{~mm}^{2}$. (C) Palito obtido para ensaio de microtração.

\section{Ensaio de resistência de união a microtração ( $\mu$ TBS)}

No teste de microtração, foi utilizado a máquina universal de ensaios (Instron Corporation, Canton-Massachusetts, EUA) com célula de carga de $50 \mathrm{Kg} / \mathrm{f}$. Os palitos foram fixados em dispositivo de aço inoxidável com adesivo cianoacrílico (Super Bonder; Henkel Ltda, São Paulo, SP, Brasil) e submetidos a força de tração com velocidade de $0.5 \mathrm{~mm} / \mathrm{min}$ até a falha (Figura 7). Os resultados obtidos da resistência adesiva foram expressos em megapascal ( $\mathrm{MPa}$ ), fornecidos pelo 
programa por meio do cálculo das secções transversais dos palitos, medidas previamente ao teste.

As superfícies envolvidas na fratura de cada espécime foram analisadas no microscópio óptico (Axiostarplus, Carl Zeiss, Jena, Germany), e classificadas de acordo com o padrão de fratura. Foram inclusas dentro do grupo de falhas adesivas, aquelas onde a superfície dentinária estivesse coberta por uma fina camada de material adesivo. O grupo de falhas coesivas do material, quando a superfície estivesse coberta por resina composta; coesivas do substrato, quando a falha ocorresse na dentina; e mista, quando se encontrasse uma combinação dos tipos adesiva e coesiva.
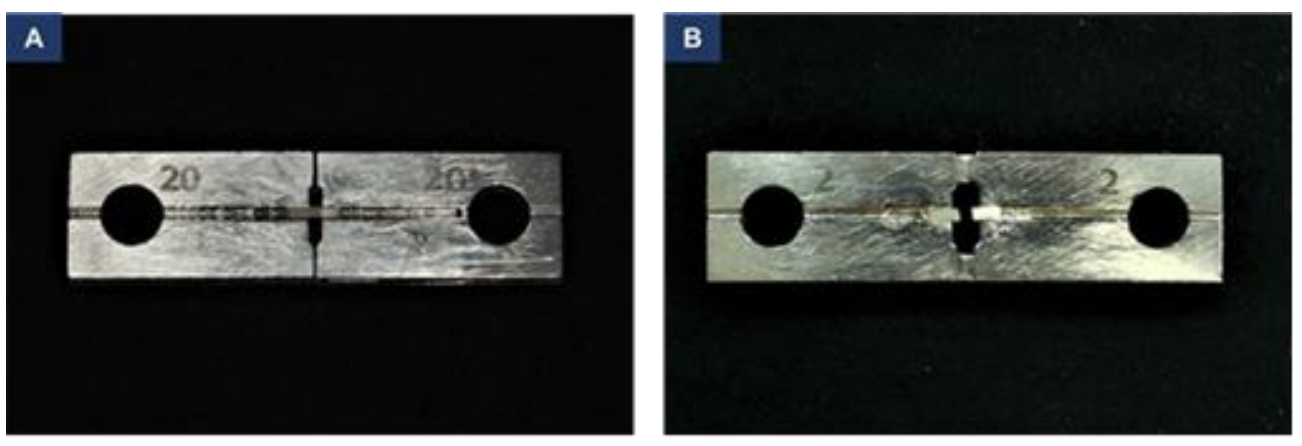

Figura 7 - Ensaio de microtração. (A) Fixação do palito no dispositivo de aço inoxidável. (B) Palito após o teste.

\section{Microscopia Electrónica de Varredura (MEV) da interface adesiva}

Após a restauração, os espécimes foram seccionados no centro e uma das metades foi aleatoriamente destinada à análise em microscopia eletrônica de varredura $(n=3)$. Os espécimes foram fixos em anéis de resina acrílica e a interface adesiva foi polida com lixa d'água de granulação \#1200e em seguida, com disco de feltro e pastas de alumina de granulação de $0.3 \mu \mathrm{m}$ e $0.05 \mu \mathrm{m}$ (Arotec S/A Ind. Com., São Paulo, Brasil).

Após o polimento, foi aplicado ácido fosfórico a 35\% (Ultra-Etch Ultradent, SP, Brazil) sobre toda a interface adesiva por 10 segundos. A superfície foi lavada com água destilada e seca em papel absorvente. Os espécimes foram imersos em glutaraldeído a $2.5 \%$ com cacodilato de sódio $0.1 \mathrm{M}$ (Merck KGaA, Darmstadt, 
D-64293, Germany) por um período de 12 horas. Após este período, foi aplicado EDTA a $37 \%$ por 30 segundos, seguida de lavagem em água destilada. Os espécimes foram desidratados na sequência de etanol de $25^{\circ}, 50^{\circ}, 75^{\circ}, 95^{\circ} \mathrm{GL}$, mediante imersão por 20 minutos em cada solução, finalizando com a imersão, por 1 hora, em etanol $100^{\circ} \mathrm{GL}$. Finalizada a desidratação, foram fixos novamente em stubs metálicos e cobertos com fina camada da liga ouro-paladium em aparelho de metalização a vácuo (Bal-Tec AG, Balzers, Liechtenstein). A seguir foram levados ao Microscópio Eletrônico de Varredura (EVO 50; Carl Zeiss, Cambridge, Inglaterra) pertencente ao Laboratório de Microscopia Eletrônica de Varredura do Departamento de Química da Faculdade de Filosofia Ciências e Letras, Ribeirão Preto, SP.

Foi realizada a varredura de toda a interface adesiva e, em seguida, fotografada a área mais representativa de cada grupo em aumento de 1.500x.

\section{Análise estatística}

Os dados foram analisados quanto à aderência a curva normal. Para aqueles que apresentaram distribuição normal foi realizada Análise de Variância (ANOVA), seguida de teste de Bonferroni. Os dados que apresentaram distribuição não normal foram analisados pelo teste de Friedman e pós teste de Wilcoxon. Foi determinado o nível de significância de $5 \%$ e os cálculos estatísticos foram realizados utilizando o programa IBM SPSS Statistics versão 20.0 (SPSS Inc., v20, Armonk, NYL, EUA). 
Resultados 



\section{RESULTADOS}

A Figura 8 mostra o intervalo de confiança $(95 \%$ IC) das medidas de microdureza. Medições foram obtidas em quatro períodos: na dentina hígida, na dentina afetada por cárie, após a remoção seletiva da lesão de cárie (dentina residual) e após a restauração dos espécimes. Intersecções entre os intervalos foram encontradas após a biomodificação ou não da dentina residual, seguida da restauração em resina composta.

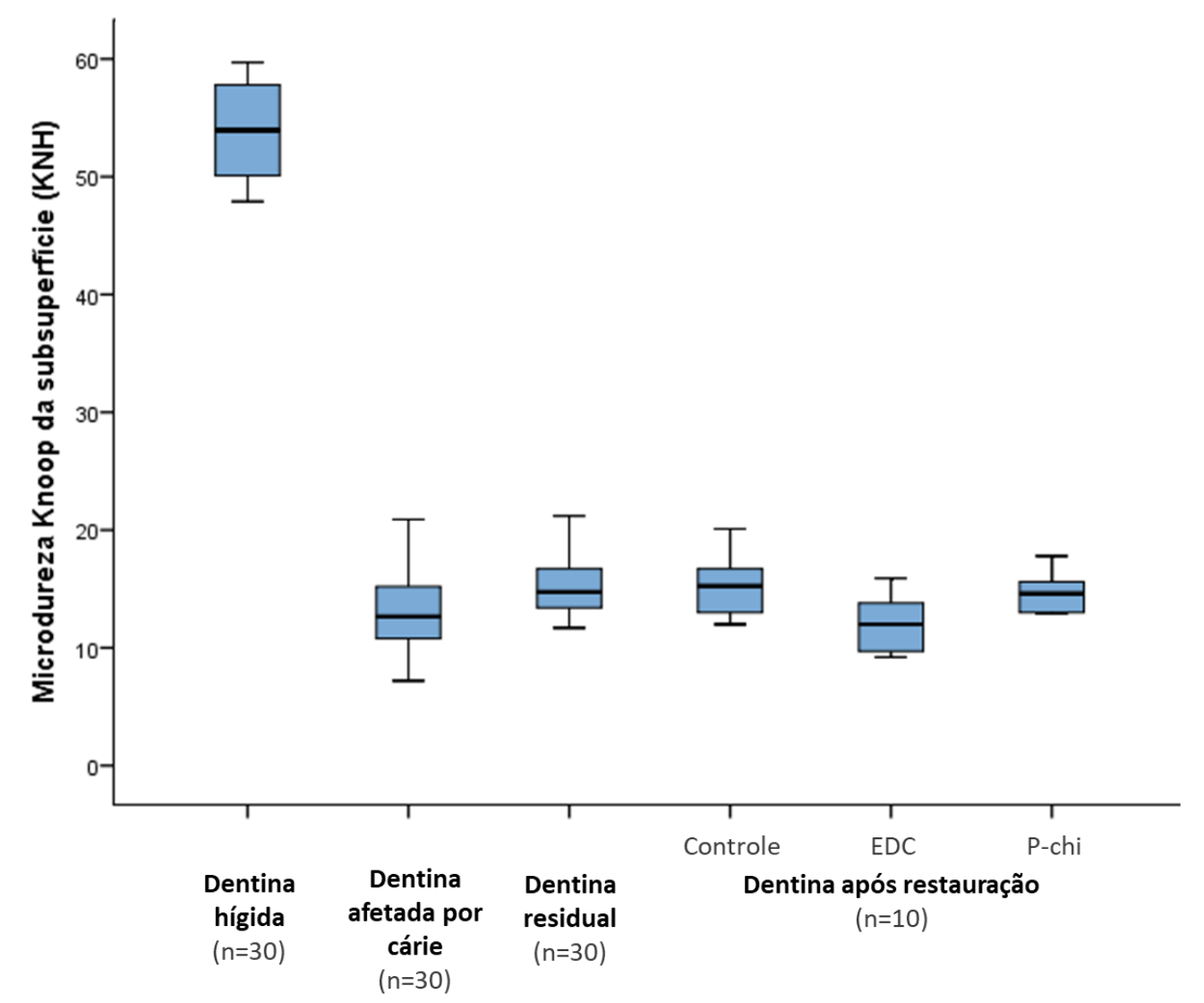

Figura 8 Intervalo de confiança (95\% IC) das medições de microdureza.

Os resultados (medianas e IC 95\%) do teste de microdureza e as comparações estatísticas de todos os grupos estão apresentadas nas tabelas 1 e 2 . A tabela 1 mostra que a indução artificial das lesões de cárie promoveu uma diminuição da microdureza da subsuperfície dentinária $(p<0,001)$. No entanto após remoção seletiva da lesão de cárie houve aumento da microdureza $(p<0,001)$. 
Tabela 1 Mediana (95\% IC) da microdureza de subsuperfície da dentina $(n=30)$.

\section{CONDIÇÃO DENTINÁRIA}

\begin{tabular}{ccc} 
Hígida & Afetada por cárie & Residual \\
\hline $53,95(52,62-55,54)$ a & $12,65(11,55-14,01) \mathrm{c}$ & $14,75(14,55-17,57) \mathrm{b}$ \\
\hline
\end{tabular}

Letras minúsculas indicam semelhança estatística entre colunas.

(Teste de Friedman e pós teste de Wilcoxon; $p>0,05$ ).

A biomodificação da dentina residual afetada por cárie com P-chi ou EDC, seguida do procedimento restaurador, não alterou a microdureza da subsuperfície dentinária $(\mathrm{p}=0,141)$ (Tabela 2$)$.

Tabela 2 Media (desvio padrão) da microdureza de subsuperfície da dentina após biomodificação e restauração $(n=10)$.

\section{BIOMODIFICAÇÃO}

\begin{tabular}{ccc} 
Controle & EDC & P-chi \\
\hline $15,27(2.81)$ & $12,55(3,38)$ & $14,60(3,05)$ \\
\hline
\end{tabular}

Não houve diferença significativa entre os grupos (Teste de ANOVA simples; $p>0,05$ ).

Com relação aos resultados obtidos no teste de resistência de união por ensaio de microtração, para melhor visualização dos resultados, a tabela 3 ilustra as comparações estatísticas obtidas pela ANOVA.

Os fatores em estudo, tempo ( $p=0,210)$ e biomodificação da dentina $(p=0,365)$ de forma isolada, não influenciaram os valores da resistência de união à dentina (Tabela 3). 
Tabela 3 Comparações estatísticas entre os fatores de estudo realizadas pela Análise de Variância.

\begin{tabular}{lcc}
\hline \multicolumn{1}{c}{ Fatores } & F & Valor de $\mathbf{p}$ \\
\hline Tempo & 1,634 & 0.210 \\
Biomodificação & 1,038 & 0,365 \\
Tempo * Biomodificação & 11,130 & $<0,001$ \\
\hline
\end{tabular}

No entanto, a interação entre os fatores tempo de armazenamento e biomodificação da dentina foi significante $(p<0,001)$. Verificou-se que ao longo do tempo, o grupo controle $(p<0,001)$ teve uma redução dos valores de $\mu$ TBS, o grupo EDC $(p=0,099)$ manteve os valores de $\mu$ TBS e o grupo $P$-chi $(p=0,005)$ promoveu aumento dos valores de $\mu$ TBS. Não foram encontradas diferenças significativas entre os grupos, tanto às $24 \mathrm{~h}$ como aos 6 meses de armazenamento (Tabela 4).

Tabela 4 Média (Desvio Padrão) dos valores de $\mu$ TBS da interação de todos os fatores de estudo.

\begin{tabular}{cccc}
\hline \multirow{2}{*}{$\begin{array}{c}\text { Tempo de } \\
\text { armazenamento }\end{array}$} & \multicolumn{3}{c}{ Biomodificação } \\
\cline { 2 - 4 } & Controle & EDC & P-chi \\
\hline $24 \mathrm{~h}$ & $23,92(4,57) \mathrm{Aa}$ & $21,88(5.10) \mathrm{Aa}$ & $19,54(5,31) \mathrm{Ab}$ \\
$6 \mathrm{~m}$ & $22,21(4,42) \mathrm{Ab}$ & $21,05(3,40) \mathrm{Aa}$ & $20,99(5,93) \mathrm{Aa}$ \\
\hline $\begin{array}{l}\text { Letras maiúsculas iguais indicam semelhança estatística entre colunas. } \\
\text { Letras minúsculas iguais indicam semelhança estatística entre linhas } \\
\text { (ANOVA de múltiplas comparações com ajuste de Bonferroni, } p>0,05) .\end{array}$
\end{tabular}

De acordo com a avaliação e classificação dos padrões de fratura obtidos para os diferentes grupos, observou-se predomínio de fraturas do tipo mista tanto para os palitos submetidos a $24 \mathrm{~h}$ como os de 6 meses de armazenamento em água. Os valores percentuais dos padrões de fratura estão representados na Figura 9. 


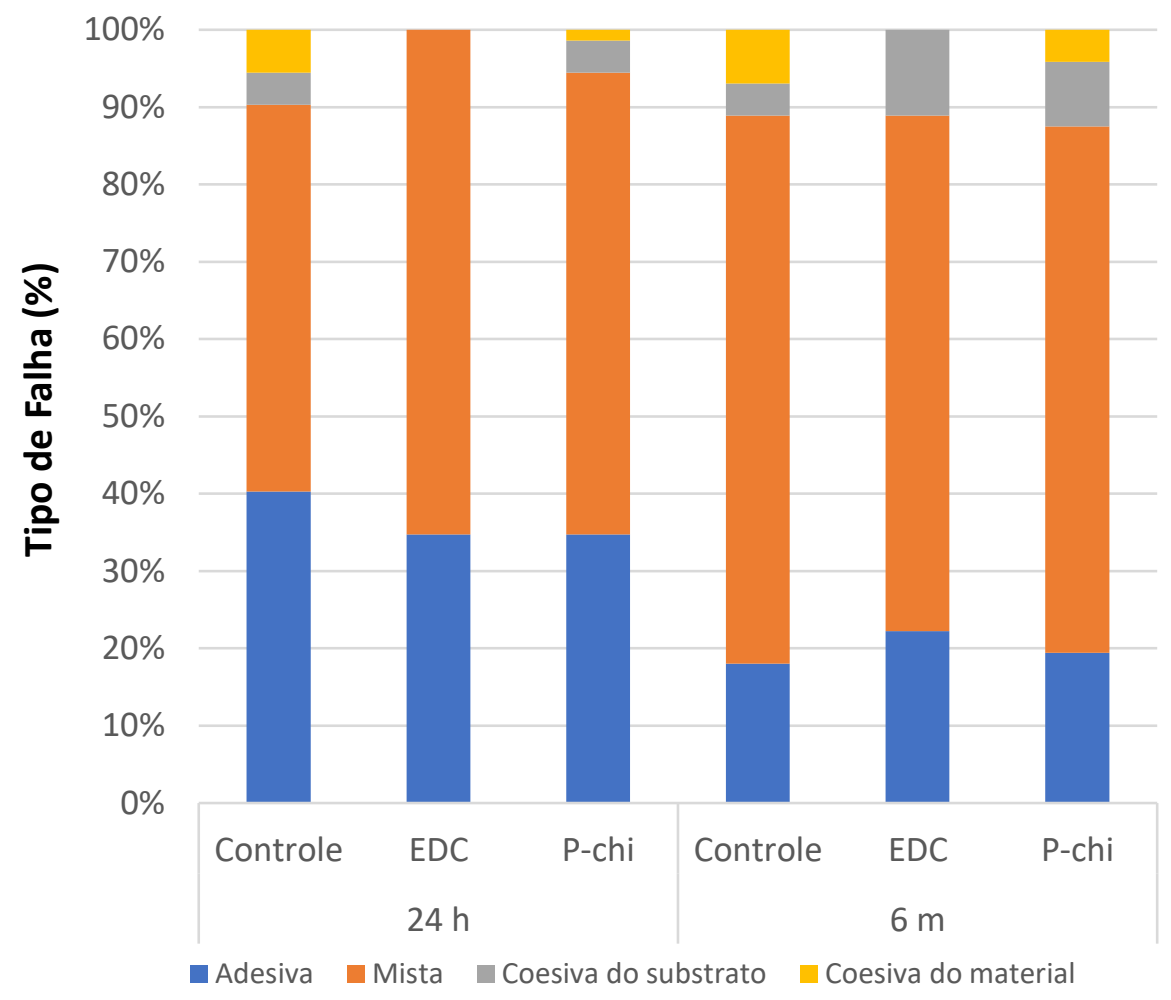

Figura 9 Porcentagem dos padrões de fraturas para os espécimes estudados.

$\mathrm{Na}$ análise morfológica da interface adesiva após 24 horas de armazenamento em água, foi possível verificar nas imagens interfaces adesivas uniformes e que todos os tratamentos promoveram formação de tags resinosos no tecido dentinário. Após de 6 meses, as interfaces adesivas mantiveram-se preservadas e sem a presença de gaps (Figura 10). 


\section{Controle}
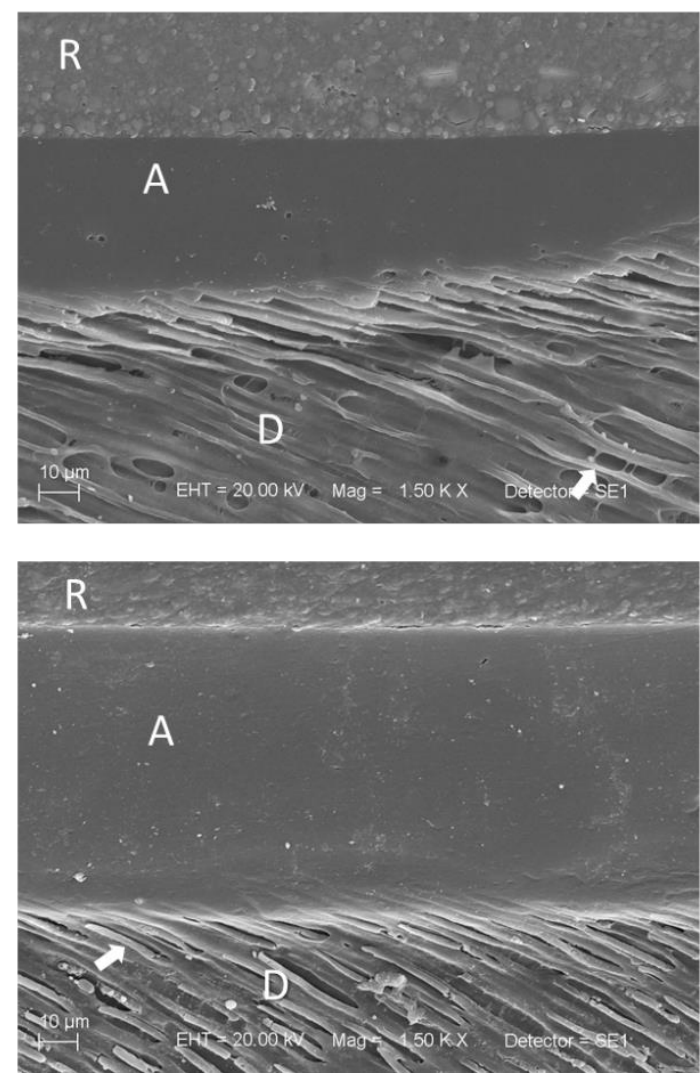

EDC
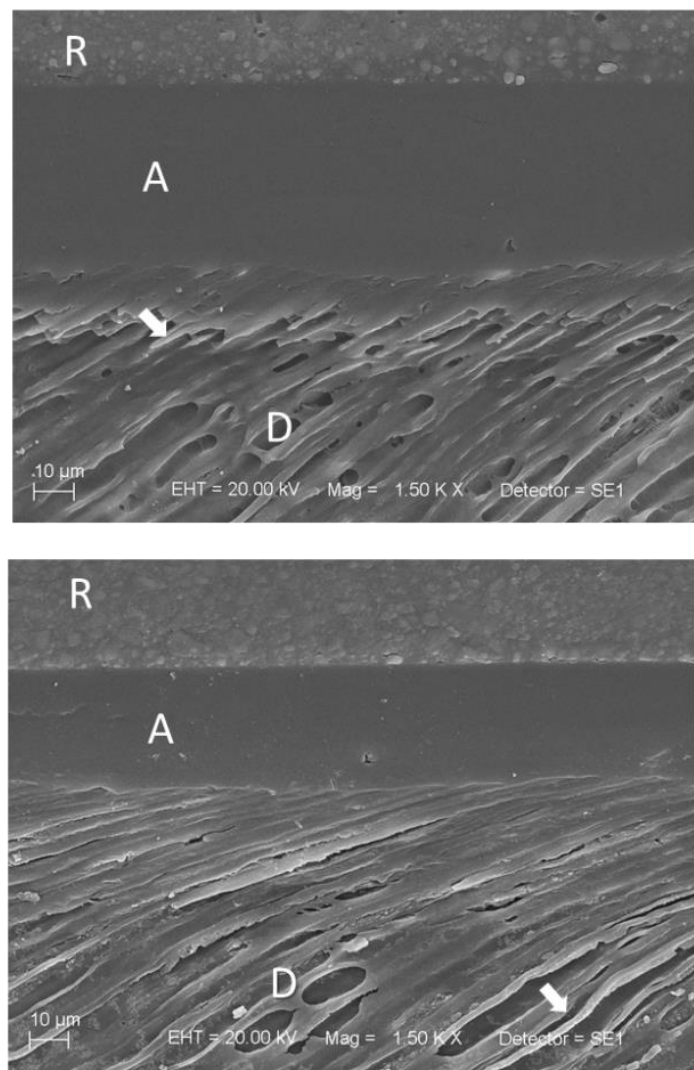

P-chi
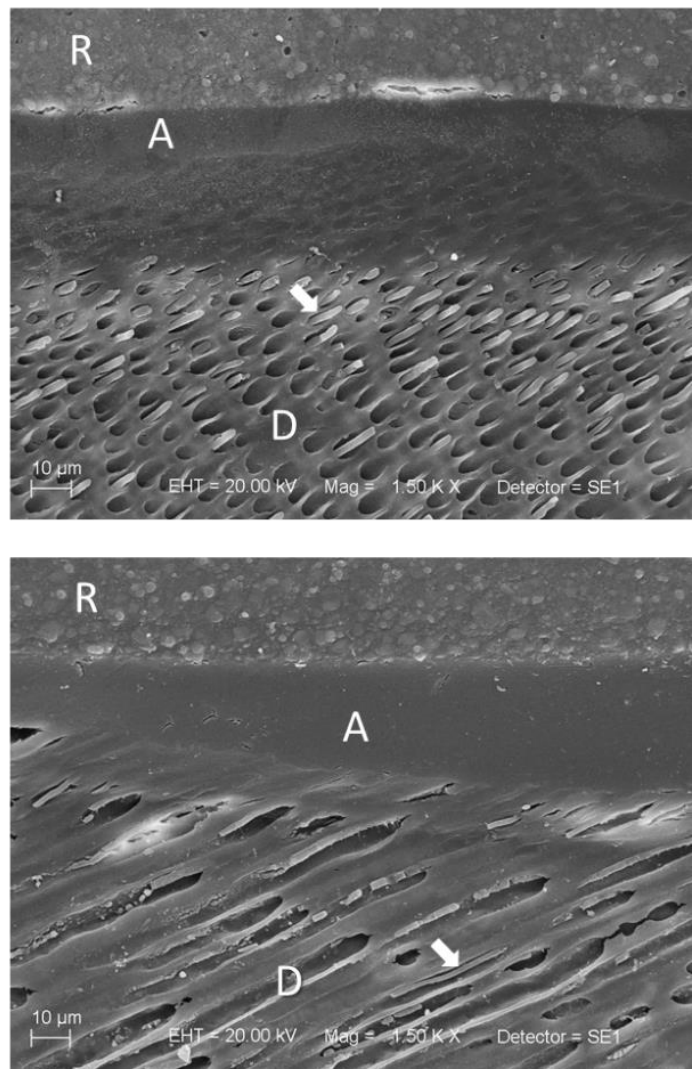

Figura 10 - Fotomicrografías representativas das interfaces adesivas dos diferentes grupos no Microscópio Eletrônico de Varredura. $\mathrm{R}=$ Resina composta. $\mathrm{A}=$ Adesivo. $\mathrm{D}=$ Dentina. $\Rightarrow$ = Indica a presença de tags resinosos. Imagens em aumento de $1.500 x$. 




\section{DISCUSSÃO}

A cárie dentária é uma doença infecciosa multifatorial, e esse conhecimento modificou a abordagem terapêutica dos elementos dentários comprometidos. A odontologia moderna segue os princípios de mínima intervenção, que tem como principal objetivo a eliminação apenas do tecido infectado e irreversivelmente desmineralizado (FUSAYAMA, 1979). Assim durante a realização da remoção da lesão de cárie nas paredes de fundo deve-se manter a dentina afetada (HILTON; SUMMITT, 2000), e nas paredes circundantes para obtenção de perfeito selamento há necessidade da remoção da dentina desmineralizada (KIDD; RICKETTS; BEIGHTON, 1996).

Sabe-se que a dentina é composta por uma matriz orgânica, principalmente colágeno tipo I, e uma fase inorgânica de apatita nanocristalina carbonatada (RAUM et al., 2007). A fase inorgânica contribui, para a resistência a compressão, o que pode afetar diretamente a microdureza, já a fase orgânica proporciona elasticidade a dentina (KINNEY; MARSHALL SJ; MARSHALL GW, 2003). Qualquer alteração em alguma destas duas fases pode contribuir para a modificação das propriedades físicas, microdureza e módulo de elasticidade do tecido (SENAWONGSE et al., 2006).

A microdureza é um método utilizado para analisar tantos materiais restauradores como tecidos biológicos e é definida pela resistência do substrato à deformação local, sendo mensurada pela relação entre a força aplicada e a área de endentação (VAN MEERBECK et al., 1993; BANERJEE; KIDD; WATSON, 2000). A microdureza da dentina depende da concentração mineral presente no substrato dentinário (SHANNON; KEUPER, 1976; FEATHERSTONE et al., 1983; ARENDS; TEM BOSCH, 1992).

Frente às relevantes características das soluções biomodificadoras e com o intuito de favorecer o processo de remineralização, neste estudo foram aplicados compostos biomodificadores, carbodiimida e quitosana fosforilada, sobre a dentina residual afetada por cárie. Os resultados demonstraram que esta biomodificação da dentina, não alterou a microdureza da subsuperfície. 
Poder ser especulado que o efeito das ligações cruzadas ocasionadas pela carbodiimida num substrato parcialmente desmineralizado por um tempo de aplicação de 60 segundos e a uma concentração de $0.5 \mathrm{~mol} / \mathrm{L}$, não foi o suficiente para produzir alguma alteração na composição da dentina que pudesse ser detectada pela análise de microdureza. A utilização da carbodiimida como agente biomodificador aparentemente não melhora a dureza superficial, nem as propriedades mecânicas da dentina desmineralizada (ABUELENAIN et al., 2017). A ausência de efeito remineralizante por parte da quitosana fosforilada pode ser resultante da incapacidade do agente de alterar por a fase mineral, sem mobilização de íons como cálcio ou fósforo ao substrato desmineralizado, o que poderia permitir a regeneração e remineralização do mesmo. No estudo de Curyloffo-zotti et al. (2017), a aplicação de quitosana não afetou os componentes inorgânicos da dentina, não afetando a quantidade de cálcio, fósforo e a proporção cálcio/fósforo dos cristais de hidroxiapatita. Por tanto não houve alterações na microdureza da subsuperfície dentinária.

Xu et al. (2011) utilizou quitosana fosforilada com o objetivo de remineralizar a dentina parcialmente desmineralizada. Neste estudo foram utilizados dois protocolos diferentes de aplicação do agente biomodificador. No primeiro a dentina foi imersa na solução biomodificadora até que esta fosse totalmente volatilizada, e não houve remineralização do substrato desmineralizado. No segundo protocolo, a dentina foi imersa na solução de quitosana fosforilada associada a glutaraldeído (agente potencializador das ligações cruzadas) por um período de $24 \mathrm{~h}$, com deposição de minerais cálcio e fósforo, ou seja, a remineralização da dentina. Estes resultados confirmaram que a ação da quitosana fosforilada isoladamente não é suficiente para remineralização da dentina, porém, sua associação com algum agente promotor de ligações cruzadas, poderia possibilitar a remineralização da dentina.

Sabe-se que a união resina-dentina utilizando sistemas adesivos poder sofrer um processo de deterioração ao longo do tempo (MAZZONI et al., 2006; TJÄDERHANE et al., 2013; TJÄDERHANE, 2015) devido a atividade hidrolítica das proteases e endopeptidases (metaloproteinases e catepsinas) capazes de degradar as proteínas extracelulares (PASHLEY et al., 2004; CARRILHO et al., 2007; OBERMAJER et al., 2008). A dissolução mineral e a degradação colágena enzimática podem interferir na qualidade da rede colágena (SABATINI; PASHLEY, 
2014). Assim, o tratamento da dentina com sistemas adesivos etch and rinse ou selfetch pode ativar as formas precursoras destas enzimas que poderiam ter permanecido inativas (MAZZONI et al., 2006).

A resistência de união da resina composta à dentina afetada por cárie foi avaliada neste estudo após a biomodificação da dentina. Os resultados demonstraram que os grupos tratados com os biomodificadores apresentaram resistência de união semelhante a ao grupo controle no período de 24 horas. Ao longo do tempo a biomodificação com carbodiimida foi capaz de manter os valores de resistência de união, enquanto a quitosana fosforilada promoveu aumento.

A biomodificação de estruturas de tecidos duros como a dentina tem sido utilizada na tentativa de melhorar as propriedades biomecânicas e bioquímicas do tecido para fins preventivos ou reparadores/ restauradores (BEDRAN-RUSSO et al., 2014). O desenvolvimento destas estratégias biomodificadoras permite um aumento no número de ligações cruzadas do colágeno, melhorando as propriedades do tecido e sua estabilidade mediante interação química (TJÄDERHANE et.al., 2015). O aumento destas ligações cruzadas conferem estabilidade, força e viscoelasticidade à matriz colágena dentinária (TJÄDERHANE et.al., 2015).

Os resultados do presente estudo estão de acordo com estudos anteriores que demonstraram que a carbodiimida pode melhorar a durabilidade das restaurações adesivas mediante o aumento das propriedades mecânicas da matriz colágena, reduzindo a susceptibilidade das fibrilas colágenas à degradação enzimática pelas colagenases (LIU et al., 2011). Quando utilizada a $0.5 \mathrm{~mol} / \mathrm{L}$ por 60 segundos previamente ao procedimento adesivo preveniu a degradação da interface adesiva (SCHEFFEL et al., 2015) e na concentração de $0.3 \mathrm{~mol} / \mathrm{L}$ foi capaz de inativar as MMPs, preservando a resistência de união ao longo do tempo (MAZZONI et al., 2013). O uso de quitosana foi capaz inibir o efeito, in vitro, da degradação de matrizes de colágeno por Clostridium histolyticum (PERSADMEHR et al., 2014). Outros estudos constaram que o uso de quitosana associada a outro composto, após o condicionamento com ácido fosfórico, promoveu aumento da força de adesão imediata (FAWZY et al., 2013) e melhora na infiltração do adesivo na dentina hígida (DAOOD et al., 2013). No entanto, comparações diretas com os resultados deste 
72 | DISCUSSÃO

estudo tornam-se dificultadas devido à ausência de estudos que avaliaram o efeito da quitosana fosforilada na resistência de união à dentina afetada por cárie.

A carbodiimida e a quitosana fosforilada demonstram-se alternativas promissoras para a biomodificação da dentina afetada por cárie. No entanto, estudos futuros que avaliem a aplicação in vivo destes agentes são necessários. 
Ponclus̃ão 



\section{CONCLUSÃO}

De acordo com os resultados deste estudo, pode-se concluir que:

1. A biomodificação com carbodiimida e quitosana fosforilada não influenciou a microdureza da subsuperfície da dentina afetada por cárie.

2. A biomodificação com carbodiimida e quitosana fosforilada foi capaz de inibir a degradação da interface adesiva, mantendo a resistência de união da resina composta à dentina afetada por cárie após 6 meses de armazenamento em água. 

Referêncios 



\section{REFERÊNCIAS}

ABUELENAIN, D. A., NEEL, E. A. A., ABU-HAIMED, T. Effects of dentin modifiers on surface and mechanical properties of acid-etched dentin. International Journal of Adhesion and Adhesives. 2017. [Epub ahead of print] Disponível em:< https://www.sciencedirect.com/science/article/pii/S0143749617301999>. Acesso em: 3 dic. 2017.

ARENDS, J., TEN BOSCH, J. J. Demineralization and remineralization evaluation techniques. Journal of Dental Research. v.71, p.924-948. 1992.

BANERJEE, A., KIDD, E. A., WATSON, T. F. In vitro evaluation of five alternative methods of carious dentine excavation. Caries Research. v.34, n.2, p.144-150. 2000.

BEDRAN-RUSSO, A. K. et al. Long-term Effect of carbodiimide on dentin matrix and resin-dentin bonds. Journal of Biomedical material research. Part B, Applied Biomaterials. v.94, n.1, p.250-255. 2010.

BEDRAN-RUSSO, A. K. et al. Dentin biomodification: strategies, renewable resources and clinical applications. Dental Materials. v.30, n.1, p.62-76. 2014.

BERNKOP-SCHNÜRCH A. Chitosan and its derivatives: potential excipients for peroral peptide delivery systems. International journal of pharmaceutics. v.194, n.1, p.1-13. 2000.

CARRILHO, M. R. O. et al. In vivo preservation of the hybrid layer by chlorhexidine. Journal of dental research. v.86, n.6, p.529-533. 2007.

CHESNUTT, B. M. et al. Characterization of biomimetic calcium phosphate on phosphorylated chitosan films. Journal of Biomedical Materials Research Part A. v.82, n.2, p.343-353. 2007.

CURYLOFO-ZOTTI, F. A. et al. Selective removal of carious lesion with Er: YAG laser followed by dentin biomodification with chitosan. Lasers in Medical Science. v.32, n.7, p.1595-1603. 2017 
DAOOD, U. et al. Effect of chitosan/riboflavin modification on resin/dentin interface: Spectroscopic and microscopic investigations. Journal of Biomedical Materials Research. Part A. v.101, n.7, p.1846-1856. 2013.

EKAMBARAM, M., YIU, C. K., MATINLINNA, J. P. Effect of Solvents on Dentin Collagen Cross-Linking Potential of Carbodiimide. Journal of Adhesive Dentistry. v.17, n.3, p.219-226. 2015.

ELSAKA, S., ELNAGHY, A. Effect of addition of chitosan to self-etching primer: antibacterial activity and push-out bond strength to radicular dentin. Journal of Biomedical Research. v.26, n.4, p.288-294. 2012.

FAWZY, A. S. et al. Chitosan/Riboflavin-modified demineralized dentin as a potential substrate for bonding. Journal of the Mechanical Behavior of Biomedical Materials. v.17, p. 278-289. 2013.

FEATHERSTONE, J. D. et al. Comparison of artificial caries-like lesion by quantitative microradiography and microhardness profile. Caries Research. v.17, n.5, p.385-391. 1983.

FUSAYAMA, T. Two layers of carious dentin; diagnosis and treatment. Operative Dentistry. v.4, n.2, p.63-70. 1979.

HARA, A. T. et al. Caries progression and inhibition in human and bovine root dentine in situ. Caries Research. v.37, n.5, p.339-344. 2003.

HARA, A. T. et al. Influence of fluoride-releasing restorative material on root dentine secondary caries in situ. Caries Research. v.40, n.5, p.435-439. 2006.

HILTON TJ, SUMMITT JB: Pulpal considerations; in Summitt JB, Robbins JW, Schwartz RS (eds): Operative Dentistry. Chicago, Quintessence Publishing Co, Inc, 2000, p 103.

KIDD, E. A. M., RICKETTS, D., BEIGHTON, D. Criteria for caries removal at the enamel-dentine junction: A clinical and microbiological study. British dental journal. v.180, n.8, p.287-291. 1996. 
KIDD, E. A. How clean must a cavity be before restoration?. Caries Research. v.38, n.3, p.305-313. 2004

KINNEY, J. H., MARSHALL, S. J., MARSHALL, G. W. The mechanical properties of human dentin: a critical review and re-evaluation of the dental literature. Critical Reviews in Oral Biology \& Medicine. v.14, n.1, p.13-29. 2003.

LAUTO, A. et al. Photochemical tissue bonding with chitosan adhesive films. BioMedical Engineering Online. v.9, n.1, p:47. 2010.

LIU, Y. et al. Limitations in bonding to dentin and experimental strategies to prevent bond degradation. Journal of Dental Research. v.90, n.8, p.953-968. 2011.

LONGHI, M. et al. The effects of host derived metalloproteinases on dentin bond and the role of MMPs inhibitors on dentin matrix degradation. Oral \& Implantology. v.7, n.3, n.71-79. 2015.

MARQUEZAN, M. et al. Artificial methods of dentine caries induction: A hardness and morphological comparative study. Archives of Oral Biology. v.54, n.12, p.11111117. 2009.

MAZZONI, A. et al. Reactivation of inactivated endogenous proteolytic activities in phosphoric acid etched dentine by etch-and-rinse adhesives. Biomaterials. v.27, n.5, p.4470-4476. 2006.

MAZZONI, A. et al. Effect of carbodiimide (EDC) on the bond stability of etch-andrinse adhesive systems. Dental Materials. v.29, n.10, p.1040-1047. 2013.

MAZZONI, A. et al. Carbodiimide inactivation of MMPs and effect on dentin bonding. Journal of Dental Research. v.93, n.3, p.263-268. 2014.

MORI, T. et al. Effects of chitin and its derivatives on the proliferation and cytokine production of fibroblasts in vitro. Biomaterials. v.18, n.13, p.947-951. 1997.

MUZZARELLI, R. Chitosan. in: Muzzarelli, R. Natural Chelating Polymers. Pergamon Press. Oxford, 1973. p 144-176. 
OBERMAJER, N. et al. Role of cysteine cathepsins in matrix degradation and cell signalling. Connective tissue research. v.49, n.3-4, p.193-196. 2008

OLDE DAMINK, L. H. et al. In vitro degradation of dermal sheep collagen crosslinked using a water-soluble carbodiimide. Biomaterials. v.17, n.7, p.679-684. 1996.

PASHLEY, D. H. et al. Collagen degradation by host-derived enzymes during aging. Journal of dental research. v.83, n.3, p.216-221. 2004.

PERSADMEHR, A. et al. Bioactive chitosan nanoparticles and photodynamic therapy inhibit collagen degradation in vitro. Journal of endodontics. v.40, n.5, p.703-709. 2014.

PROFETA, A. C. et al. Bioactive effects of a calcium/sodium phosphosilicate on the resin-dentine interface: a microtensile bond strength, scanning electron and confocal microscopy study. European Journal of Oral Sciences. v.120, n.4, p.353-362. 2012.

RABEA, E. I. et al. Chitosan as antimicrobial agent: applications and mode of action. Biomacromolecules. v.4, n.6, p.1457-1465. 2003.

RAUM, K. et al. Preservation of microelastic properties of dentin and tooth enamel in vitro-a scanning acoustic microscopy study. Dental Materials. v.23, n.10, p.12211228. 2007.

RICKETTS, D. N. et al. Complete or ultraconservative removal of decayed tissue in unfilled teeth. The Cochrane Library. v.3, n.CD003808. 2006.

RODRIGUES, L. K., NOBRE DOS SANTOS, M., FEATHERSTONE, J. D. In situ mineral loss inhibition by $\mathrm{CO} 2$ laser and fluoride. Journal of Dental Research. v.85, n.7, p.617-621. 2006.

SABATINI, C., PASHLEY, D. H. Mechanisms Regulating the Degradation of Dentin Matrices by Endogenous Dentin Proteases and their Role in Dental Adhesion. A Review. American Journal of Dentistry. v.27, n.4, p.203-214. 2014.

SANO, $\mathrm{H}$. et al. Effect of rinsing with phosphorylated chitosan on four-day plaque regrowth. The Bulletin of Tokyo Dental College. v.42, n.4, p.251-256. 2001. 
SCHEFFEL, D. L. et al. Stabilization of dentin matrix after cross-linking treatments, in vitro. Dental Materials. v.30, n.2, p.227-233. 2014a.

SCHEFFEL, D. L. et al. Inactivation of matrix-bound matrix metalloproteinases by cross-linking agents in acid-etched dentin. Operative Dentistry. v.39, n.2, p.152-158. 2014b.

SCHEFFEL, D. L. et al. Increased Durability of Resin-Dentin Bonds Following CrossLinking Treatment. Operative Dentistry. v.40, n.5, p.533-539. 2015.

SENAWONGSE, P. et al. Age-related changes in hardness and modulus of elasticity of dentine. Archives of Oral Biology. v.51, n.6, p.457-463. 2006.

SHAFIEI, F., YOUSEFIPOUR, B., MOHAMMADI-BASSIR, M. Effect of Carbodiimide on Bonding Durability of Adhesive-cemented Fiber Posts in Root Canals. Operative Dentistry. v.41, n.4, p.432-440. 2016.

SHANNON, I. L., KEUPER, J. B. Microhardness of human dentin: baseline values and effect of fluorides. Journal of Missouri Dental Association. v.56, n.9, p.11-18. 1976.

SILVA, P. V. et al. Time-dependent effects of chitosan on dentin structures. Brazilian Dental Journal. v.23, n.4, p.357-361. 2012.

SINGH, P. et al. Effect of carbodiimide on the structural stability of resin/dentin interface. Journal of Conservative Dentistry. v.19, n.6, p.501-509. 2016.

TANGSADTHAKUN, C. et al. The influence of molecular weight of chitosan on the physical and biological properties of collagen/chitosan scaffolds. Journal of Biomaterials Science Polymer Edition. v.18, n.2, p.147-163. 2007.

TJÄDERHANE, L. et al. Optimizing dentin bond durability: strategies to prevent hydrolytic degradation of the hybrid layer. Dental Materials. v.29, n.10, p.999-1011. 2013.

TJÄDERHANE, L. Dentin Bonding: Can We Make it Last?. Operative Dentistry. v.40, n.1, p.4-18. 2015. 
TYAS, M. J. et al. Minimal intervention dentistry-a review. International Dental Journal. v.50, n.1, p.1-12. 2000.

VAN MEERBECK, B. et al. Assessment by nanoindentation of the hardness and elasticity of the resin-dentin bonding area. Journal of Dental Research. v.72, n.10, p.1434-1442. 1993.

WANG, X. H. et al. Crosslinked collagen/chitosan matrix for artificial livers. Biomaterials. v.24, n.19, p.3213-3220. 2003.

WANG, K., LIU, Q. Chemical structure analyses of phosphorylated chitosan. Carbohydrate Research. v.386, p.48-56. 2014.

WALSH, L. J., BROSTEK, A. M. Minimum intervention dentistry principles and objectives. Australian Dental Journal. v.58, n.1, p.3-16. 2013.

$\mathrm{XU}$, Z. et al. Biomimetic deposition of calcium phosphate minerals on the surface of partially demineralized dentine modified with phosphorylated chitosan. Journal of Biomedical Materials Research Part B: Applied Biomaterials. v.98, n.1, p.150159. 2011.

YOKOGAWA, Y. et al. Growth of calcium phosphate on phosphorylated chitin fibres. Journal of Materials Science: Materials in Medicine. v.8, n.7, p.407-412. 1997.

ZEEMAN, R. et al. Successive epoxy and carbodiimide cross-linking of dermal sheep collagen. Biomaterials. v.20, n.10, p.921-931. 1999. 